\section{Discurso relatado à luz da Semântica Argumentativa e da Gramática Normativa*}

Reported speech in the light of Argumentative Semantics and Normative Grammar

Aleise Guimarães CARVALHO (UFPB) aleiseguimaraes@yahoo.com.br Erivaldo Pereira do NASCIMENTO (UFPB) erivaldo@ccae.ufpb.br

Recebido em: 21 de jan. de 2019. Aceito em: 20 de maio de 2019.

*Texto apresentado em comunicação oral no XXVII Jornada Internacional GELNE, Recife-PE, 16 de novembro de 2018.
CARVALHO, Aleise Guimarães;

NASCIMENTO, Erivaldo Pereira do. Discurso relatado à luz da Semântica Argumentativa e da Gramática Normativa. Entrepalavras, Fortaleza, v. 9, n. 2, p. 237-255, maio-ago/2019.

Resumo: O caráter normativo e prescritivo da Gramática, dita tradicional, estabelece um padrão específico em relação ao uso de determinadas construções linguísticas, considerando apenas o aspecto estrutural da língua. Sob esse viés, a Gramática Normativa (GN) prescreve alguns fatores correspondentes ao uso e identificação das formas de discurso relatado, em suas variações. A Semântica Argumentativa (SA), por sua vez, propõe a descrição e análise dos sentidos dos enunciados, consequentemente do discurso, a partir da observação das vozes que o locutor coloca em cena na sua enunciação. Diante disso, interessou-nos observar como a GN e os estudos da Polifonia, no âmbito da SA, abordam e compreendem o discurso relatado. Dessa forma, elaboramos um estudo sobre o discurso em estilo direto e estilo indireto - especificamente pontuando a abordagem apresentada pela SA em paralelo com a abordagem da GN da Língua Portuguesa. Para tanto, utilizamos recortes de ocorrências de enunciados na forma de discurso relatado coletados no gênero acadêmico Projetos de Pesquisa de TCC, de dois cursos distintos de graduação (corpus coletado para pesquisa do nosso mestrado). Como metodologia, adotamos a análise do tipo descritiva- 
V. 9 (2)

237-255 maio-ago 2019 interpretativista, sob as concepções teóricas de Ducrot (1987; 1988); Nascimento (2009; 2015), na perspectiva da Semântica Argumentativa e Cunha (1979); Bechara (2006), na abordagem da Gramática Normativa. Observou-se que a SA apresenta uma possibilidade de análise mais voltada para o funcionamento do discurso relatado, em enunciados reais, enquanto a GN apresenta limitações de análise, dado o caráter eminentemente sintático com que trata o fenômeno pesquisado.

Palavras-chave: Discurso relatado. Semântica Argumentativa. Gramática Normativa.

Abstract: The normative and prescriptive character of Grammar, called Traditional, establishes a specific pattern in relation to the use of certain linguistic constructions, considering only the structural aspect of the language. Under this bias, Normative Grammar (NG) prescribes some factors corresponding to the use and identification of the forms of the reported speech, in their variations. The Argumentative Semantics (AS), in turn, proposes the description and analysis of the meanings of the statements, consequently of the discourse, from the observation of the voices that the speaker puts on the scene in his enunciation. On this, we were interested in observing how the NG (GN, in portuguese) and the studies of Polyphony, within the HS, approach and understand the reporte speech. In this way, we elaborated a study on the direct and indirect style discourse - specifically - punctuating the approach presented by the AS in parallel with the approach of the NG of the Portuguese Language. To do so, we used cuttings of occurrences of statements in the form of reported speech collected in the academic genre Surveys Projects (final course assignment), of two distinct undergraduate courses (corpus collected for our master's research). As a methodology, we adopted the analysis of the descriptive-interpretative type, under the theoretical conceptions of Ducrot $(1987,1988)$; Nascimento (2009; 2015), from the perspective of Argumentative Semantics and Cunha (1979); Bechara (2006), in the Normative Grammar approach. It was observed that the AS presents a possibility of a more focused analysis on the functioning of the reported speech, in real statements, while the NG presents limitations of analysis, concerning the eminently syntactic character with which it treats the phenomenon researched.

Keywords: Reported Speech. Argumentative Semantics. Normative Grammar.

\section{Introdução}

A teoria Semântica foi amplamente desenvolvida dentro do campo dos estudos linguísticos e atualmente contempla várias vertentes, as quais sugerem estudar o sentido dos enunciados evidenciando aspectos e abordagens particulares. A Semântica Argumentativa (SA) propõe a descrição e análise dos sentidos dos enunciados, consequentemente do discurso, a partir da observação das vozes que o locutor coloca em cena na sua enunciação, entre outros aspectos. Tendo em vista o estudo dessas diferentes vozes presente nos enunciados, Oswald Ducrot (1987; 1988) propõe a Teoria Polifônica da Enunciação (TPE).

Com base nos pressupostos da TPE, neste trabalho apresentaremos um estudo sobre o discurso em estilo direto e estilo indireto pontuando a abordagem apresentada pela Semântica Argumentativa em paralelo com a abordagem da Gramática Normativa 
da Língua Portuguesa. Vale salientar que a Gramática Normativa é aqui compreendida como a "lei que regula o uso da língua em uma sociedade" (TRAVAGLIA, 2001, p. 31), ou seja, aquela que prescreve alguns fatores correspondentes ao uso e identificação das formas linguísticas, no nosso caso, do discurso relatado em suas variações.

Assim, neste trabalho pretendemos refletir de que maneira a Semântica Argumentativa considera o discurso em estilo direto e indireto e qual a diferença existente entre essa abordagem em relação à Gramática Normativa (GN). Para o desenvolvimento deste estudo adotaremos como metodologia a análise do tipo descritiva-interpretativista.

Para tanto, utilizaremos três exemplos de ocorrências de enunciados, na forma de discurso relatado em estilo direto e/ou estilo indireto, retirados do corpus de análise da nossa dissertação de mestrado ${ }^{1}$ concluída no ano de 2014, defendida no Programa de Pós-Graduação em Linguística da Universidade Federal da Paraíba (PROLING) e filiada ao projeto Estudos Semânticos Argumentativos de Gêneros do Discurso (ESAGD). Esse corpus é composto por 16 (dezesseis) Projetos de Pesquisa de TCC (produção acadêmica exigida aos alunos em alguns cursos de graduação) de dois cursos distintos, curso de Licenciatura em Letras da Universidade Federal de Campina Grande (UFCG) e curso de Bacharelado em Secretariado Executivo Bilíngue da Universidade Federal da Paraíba (UFPB).

Dessa forma, dividiremos este artigo em três partes. No primeiro subtópico, apresentaremos o relatado conforme a Gramática Normativa, tendo foco nos estudos de Cunha (1979) e Bechara (2006). Na segunda seção, faremos um percurso expositivo e descritivo sobre a teoria polifônica postulada por Ducrot, apresentando as contribuições do citado teórico acerca do fenômeno da polifonia.

A partir dessa breve exposição sobre a Polifonia Enunciativa de Ducrot - importante para compreensão dos estudos sobre o discurso relatado apresentado pela SA-, focaremos nos estudos de Nascimento (2009; 2015), segundo os quais abordaremos algumas questões relativas ao discurso relatado em estilo direto, como também em estilo indireto. Posteriormente, na terceira seção traçaremos um paralelo entre a teoria a SA e a GN, realizando uma análise comparativa a fim de compreender os pontos convergentes e divergentes entre as duas análises. Por fim,

${ }^{1}$ Título da dissertação: "O arrazoado por autoridade e a modalização discursiva: estratégias de argumentação no gênero Projeto de Pesquisa de TCC". Autor: Aleise Guimarães Carvalho. Orientador: Erivaldo Pereira do Nascimento. 
V. 9 (2)

$237-255$

maio-ago 2019

teceremos algumas considerações finais acerca da discussão teórica apresentada nas primeiras partes do estudo, como também sobre a diferenciação existente entre a abordagem da SA e da GN em relação ao discurso relatado.

\section{Discurso em estilo direto, indireto e indireto livre conforma a Gramática Normativa}

Como forma de análise e estudo da abordagem normativa dos discursos relatados, aqui escolhemos utilizar as contribuições de Cunha (1979) e Bechara (2006). Em ambas gramáticas, o desenvolvimento do estudo do discurso relatado dá-se de três formas: o discurso direto; o discurso indireto e o discurso indireto livre.

Cunha e Bechara tratam os discursos como enunciados e reprodução de enunciações, no entanto os exemplos apresentados nas análises são apenas de textos literários. Nessa abordagem, os gramáticos indicam os sujeitos envolvidos nos discursos relatados como "narrador", aquele responsável pelo discurso, e "personagem", aquele sobre quem o narrador fala. Em alguns momentos, Bechara (2006) faz uso do termo "interlocutor" como sinônimo de personagem, ou seja, o outro sujeito que é referido no discurso pelo narrador.

Diante dessa primeira percepção, por contemplar somente os discursos no campo da literatura, nossa compreensão pode ser a de que os discursos relatados ocorrem apenas no texto literário, uma vez que é nesse tipo de texto que encontramos as figuras do "narrador" e "personagem". Essa é, portanto, a primeira divergência percebida entre os estudos da Semântica Argumentativa e a Gramática Normativa no que se refere à abordagem do discurso relatado. Enquanto a SA trata o discurso relatado como vozes, investigando-o em enunciados reais a partir da compreensão da Teoria Polifônica, a GN apresenta-o como classificação literária de sujeitos participantes de uma narrativa.

Com relação ao discurso direto, Cunha (1979, p. 623) diz que é a forma de expressão "em que o personagem é chamado a apresentar as suas próprias palavras". Ou seja, percebemos que o autor considera que no discurso direto um outro sujeito é convidado para participar, com suas palavras, do enunciado de outro. Dessa forma, o responsável pelo enunciado traz as palavras de outro para dentro do seu discurso.

Vejamos um exemplo apresentado por esse autor (1979, p. 624): 
(1) "- Agora - acrescentou Milkau -, peço que restitua a roupa que foi o penhor do pagamento." (G. Aranha, OC, 173)

Neste exemplo, Milkau é convidado para participar da enunciação e, assim, a sua fala é reproduzida como havia sido enunciada.

Além dessas considerações, Cunha (1979) afirma que o discurso direto, no plano formal, é marcado por verbos do dizer (dicendi), como percebido no exemplo, no qual o autor usa o verbo dicendi "acrescentar" e marca a fala do outro. No caso de ausência desses verbos, segundo Cunha (1979, p. 624), "cabe ao contexto e a recursos gráficos - tais como os dois pontos, as aspas, o travessão e a mudança de linha - a função de indicar a fala do personagem". No plano expressivo,

[...] a força da narração em discurso direto provém essencialmente de sua capacidade de atualizar o episódio, fazendo emergir da situação o personagem, tornando-o vivo para o ouvinte, à maneira de uma cena teatral [...].(CUNHA, 1979, p. 624).

Essa mesma analogia ao teatro também é realizada por Ducrot (1987, p. 185) quando afirma que o desdobramento existente no discurso do primeiro e segundo locutor é utilizado "não somente para dar a conhecer o discurso atribuído a alguém, mas também para produzir um eco imitativo", do mesmo modo que acontece em uma narrativa e na organização teatral, em que o narrador principal pode inserir, no interior de sua própria fala, o relato feito por um segundo narrador.

Diferentemente de Cunha, Bechara não realiza analogia de narrativa e/ou teatro, mas apresenta a classificação de discurso direto de maneira semelhante à exposta por Cunha. Bechara (2006, p. 481) afirma que no discurso direto "reproduzimos ou supomos reproduzir fiel e textualmente as nossas palavras e as do nosso interlocutor" com ou sem a ajuda de verbos dicendi. Além desses verbos, em alguns casos, usamse verbos sentiendi, que exprimem reação psicológica do personagem, tais como: gaguejar; balbuciar; berrar; etc. Para exemplificar uma ocorrência de estilo direto, Bechara (2006, p. 482) utiliza a seguinte sentença:

(2) José Dias recusou, dizendo: É justo levar a saúde à casa de sapé do pobre (MA.4, 14). 
V. 9 (2)

237-255

maio-ago

2019

Neste trecho, percebemos que o autor traz a fala de outro tal como foi enunciada, e a introduz com verbo dicendi "dizer", seguido de dois pontos.

No que diz respeito ao discurso indireto, Cunha (1979) afirma que o narrador incorpora na sua própria fala uma informação do personagem, restringindo-se apenas a expressar o conteúdo, sem revelar nenhuma forma linguística que teria sido realmente empregada no discurso original. Então, segundo o gramático, "este processo de reproduzir enunciados chama-se discurso indireto." (CUNHA, 1979, p. 625).

No plano formal, segundo Cunha (1979), verifica-se que os discursos indiretos também são introduzidos por verbos declarativos e as falas dos personagens são estruturadas em oração subordinada substantiva, de regra desenvolvida. Mas também pode ocorrer a elipse da conjunção integrante "que", transformando a fala do personagem em oração subordinada substantiva na forma reduzida. Já no plano expressivo, Cunha (1979, p. 626) afirma que:

[...] o emprego do discurso indireto pressupõe um tipo de relato de caráter predominantemente informativo e intelectivo, sem a feição teatral e atualizadora do discurso direto. O narrador passa a subordinar a si o personagem, com retirar-lhe a forma própria da expressão. Mas não se conclua daí que o discurso indireto seja uma construção estilística pobre. É, na verdade, do emprego sabiamente dosado de um e de outro tipo de discurso que os bons escritores extraem da narrativa os mais variados efeitos artísticos, em consonância com intenções expressivas que só a análise em profundidade de uma dada obra pode revelar.

Com essa afirmação, o gramático evidencia apenas o caráter discursivo e informativo do discurso indireto, afastando deste o aspecto teatral que, segundo ele, é característica do discurso direto. Além disso, pelo fato de o narrador, com suas próprias palavras, fazer uso da fala do personagem, o que é dito pelo personagem por meio do narrador passa a ter as características do narrador, pois o dizer do personagem está agora subordinado a ele.

Vejamos esta frase de Machado de Assis, utilizada por Cunha (1979, p. 625) como exemplo de discurso indireto:

(3) "Elisário confessou que estava com sono." (OC, II, 575)

Após essas considerações, Cunha (1979) traça um paralelo de características gramaticais das principais transposições que ocorrem no discurso direto e discurso indireto. Elaboramos, portanto, um quadro ilustrativo para sintetizar as características apontadas por Cunha (1979): 
Quadro 1 - Discurso direto e indireto

\begin{tabular}{|c|c|}
\hline DISCURSO DIRETO & DISCURSO INDIRETO \\
\hline $\begin{array}{l}\text { Exemplo: } \\
\text { "- } \text { Guardo tudo o que meu neto } \\
\frac{\text { escreve }- \text { dizia ela." (A. F. Scmidt, GB, }}{32 .)}\end{array}$ & $\begin{array}{l}\text { Exemplo: } \\
\text { "Ela dizia que guardava tudo o que } \\
\text { seu neto escrevia." }\end{array}$ \\
\hline Enunciado em $1^{\mathrm{a}}$ ou $2^{\mathrm{a}}$ pessoa. & Enunciado em $3^{\mathrm{a}}$ pessoa \\
\hline Verbo enunciado no presente. & Verbo enunciado no imperfeito. \\
\hline $\begin{array}{l}\text { Verbo enunciado no pretérito } \\
\text { imperfeito. }\end{array}$ & $\begin{array}{l}\text { Verbo enunciado no pretérito mais- } \\
\text { que-perfeito. }\end{array}$ \\
\hline $\begin{array}{l}\text { Verbo enunciado no futuro do } \\
\text { presente. }\end{array}$ & $\begin{array}{l}\text { Verbo enunciado no futuro de } \\
\text { pretérito. }\end{array}$ \\
\hline Verbo no modo imperativo. & Verbos no modo subjuntivo. \\
\hline Enunciado justaposto. & $\begin{array}{l}\text { Enunciado subordinado, geralmente } \\
\text { introduzido pela integrante que. }\end{array}$ \\
\hline $\begin{array}{l}\text { Enunciado em forma interrogativa } \\
\text { direta. }\end{array}$ & $\begin{array}{l}\text { Enunciado em forma interrogativa } \\
\text { indireta. }\end{array}$ \\
\hline $\begin{array}{l}\text { Pronome demonstrativo de } 1^{\mathrm{a}} \text { (este, esta, } \\
\text { isto) ou de } 2^{\mathrm{a}} \text { pessoa (esse, essa, isso). }\end{array}$ & $\begin{array}{l}\text { Pronome demonstrativo de } 3^{\text {a }} \text { pessoa } \\
\text { (aquele, aquela, aquilo). }\end{array}$ \\
\hline Advérbio de lugar aqui. & Advérbio de lugar ali. \\
\hline
\end{tabular}
Fonte: Carvalho e Nascimento, a partir de Cunha (1979).

Bechara (2006, p. 482), de maneira sintética, apresenta o discurso indireto afirmando que os "verbos dicendi se inserem na oração principal de uma oração complexa tendo por subordinada as porções do enunciado que reproduzem as palavras próprias ou do nosso interlocutor". Dessa forma, para o gramático, o discurso indireto apresenta-se após o verbo dicendi e é introduzido pelo transpositor "que", pela dubitativa "se" e pelos pronomes e advérbios de natureza pronominal (quem, qual, onde, como, por que, quando, etc.).

Para exemplificar esse tipo de discurso, Bechara (2006, p. 482) adapta o mesmo exemplo apresentado no discurso direto para a forma de discurso indireto, vejamos:

(4) José Dias recusou, dizendo que era justo levar a saúde à casa de sapé do pobre (MA.4, 14).

Nesse exemplo, Bechara destaca a transposição do presente (discurso direto) para o pretérito imperfeito (discurso indireto). Desaparecem os dois pontos e insere-se o transpositor "que" logo após o verbo dicendi "dizer". Essa é uma ocorrência de discurso direto transformado em discurso indireto, segundo Bechara (2006). 
V. 9 (2)

237-255

maio-ago 2019
Além da apresentação do discurso direto e do discurso indireto, os gramáticos também abordam a forma de discurso indireto livre. Cunha compreende esse terceiro tipo de discurso como a

[...] forma de expressão que, ao invés de apresentar o personagem em sua voz própria (discurso direto), ou de informar objetivamente o leitor sobre o que ele teria dito (discurso indireto), aproxima narrador e personagem, dandonos a impressão de que passam a falar uníssono [...]. (CUNHA, 1979, p. 628).

O gramático explica que esse tipo de discurso combina as características das outras duas formas. Assim, o discurso indireto livre, segundo Cunha, evita os muitos usos de "quês", ocorrente no discurso indireto, como também a retirada das construções dialogadas peculiares ao discurso direto, resultando em uma narrativa mais fluente. Vejamos o exemplo apresentado pelo autor (1979, p. 629):

(5) "D. Aurora sacudiu a cabeça e afastou o juízo temerário. Para que estar catando defeitos no próximo? Eram todos irmãos. Irmãos."

Para Cunha, o trecho em destaque corresponde à fala do outro que foi incorporada pelo narrador no seu enunciado.

Ainda sobre discurso indireto livre, Bechara (2006, p. 482) diz que este "consiste em, conservando os enunciados próprios do nosso interlocutor, não fazer-lhe referência direta". Além disso, para ele, deve-se suprimir os verbos dicendi introdutores das formas indiretas e, então, reproduzir a fala dos personagens, assim esse discurso estará na forma indireta livre.

Diante do exposto, percebemos que a Gramática Normativa considera o discurso relatado de três formas distintas: direto; indireto e indireto livre. Portanto, feitas essas considerações, na próxima seção faremos um breve percurso teórico sobre a polifonia de Ducrot a fim de que a percepção do discurso relatado na SA seja compreendida com clareza. Após a seção sobre polifonia, segue o subtópico acerca do discurso relatado com base na SA. 
A polifonia enunciativa

O termo polifonia emergiu no contexto de estudos relacionados à música e, analogicamente, foi utilizado por Bakthin (2000) ao analisar textos literários. A partir dessa análise, o teórico reconheceu diversas vozes que se expressam ao mesmo tempo em um mesmo texto.

Nessa perspectiva, Ducrot (1987) afirma que a abordagem de Bakthin (2000) se diferencia da apresentada por ele pelo fato de o teórico sempre ter aplicado os estudos polifônicos aos textos e "jamais aos enunciados de que estes textos são constituídos" (1987, p. 161). Para Ducrot (1987), o sentido de um enunciado pode estar relacionado a um ou a mais sujeitos. É nesse sentido que Ducrot (1987) questiona o princípio da unicidade do sujeito falante, princípio esse cuja compreensão é a de que em um enunciado há somente uma voz que fala, o autor.

Ducrot (1987) confronta esse princípio ao afirmar que um enunciado pode ser perpassado por mais de uma voz. O locutor responsável pelo o dito coloca no enunciado certo número de personagens linguísticos e, desta maneira, não se expressa diretamente, ou seja, o sujeito que fala põe em cena algumas vozes que falam dentro do mesmo enunciado.

Assim sendo, a polifonia proposta por Ducrot (1988, p. 16) tem por objetivo mostrar que "en un mismo enunciado hay presente varios sujetos con status linguísticos diferentes". A partir deste entendimento, Ducrot elenca três conceitos para que se torne possível compreender as funções que o sujeito assume no enunciado, ou na enunciação, a saber: sujeito empírico (SE); locutor (L); enunciador (E).

O sujeito empírico é aquele que produz o enunciado, ou seja, é o sujeito que faz nascer, de maneira literal, o texto: "SE es el autor efectivo, el produtor del enunciado " (DUCROT, 1988, p. 16.). No entanto, segundo o estudioso, é muito difícil determinar quem realmente produziu tal enunciado. Como exemplo para compreendermos essa dificuldade, Ducrot (1988) reflete a respeito da produção de uma circular administrativa na qual não podemos afirmar se o texto foi produzido pela secretária, ou o funcionário que ditou a circular, ou qualquer outro sujeito dentro da empresa.

Portanto, para o autor, não compete ao semanticista compreender quem produziu efetivamente o texto, pois: 
V. 9 (2)

237-255

maio-ago 2019
Outro personagem linguístico apresentado por Ducrot (1987) é o locutor. A esse personagem o semanticista afirma ser aquela pessoa a quem se atribui a responsabilidade pelo enunciado.

Por definição, entendo por locutor um ser que é, no próprio sentido do enunciado, apresentado como seu responsável, ou seja, como alguém a quem se deve imputar a responsabilidade deste enunciado. É a ele que refere o pronome eu e as outras marcas da primeira pessoa. Mesmo que não se leve em conta, no momento, o discurso relatado direto, ressaltar-se-á que o locutor, designado por eu, pode ser distinto do autor empírico do enunciado, de seu produtor - mesmo que as duas personagens coincidam habitualmente no discurso oral (DUCROT, 1987, p. 182, [grifos do autor]).

Na citação anterior, Ducrot conceitua o locutor de um enunciado afirmando que é a ele que se referem as marcas de primeira pessoa, no entanto, não necessariamente o autor real do enunciado é também o locutor. Ao locutor imputamos a responsabilidade pelo enunciado como todo.

O enunciador Ducrot (1988, p. 20) denomina como sendo os diferentes pontos de vista que se apresentam em determinado enunciado, "no son personas sino "puntos de perspectiva" abstractos". Além do mais, Ducrot afirma que "el locutor mismo puede ser identificado con algunos de estos enunciadores, pero en la mayoría de los casos los presenta guardando cierta distancia frente a ellos" (1988, p. 20). Os enunciadores são colocados em cena no discurso pelo locutor responsável pelo enunciado e perante eles o locutor assume diferentes posicionamentos.

A partir desses três personagens linguísticos, Ducrot (1987) sugere dois tipos de polifonia, a polifonia de enunciadores e a de locutores. Em relação à primeira polifonia, Ducrot (1987) afirma que o locutor apresenta em seu enunciado diferentes pontos de vista com os quais ele se identifica, aprova ou rechaça. Por meio destas diferentes vozes e diferentes pontos de vista, o locutor orienta o sentido pretendido do enunciado. Concernente à polifonia de locutores, o semanticista afirma que consiste naquele tipo em que o locutor responsável pelo enunciado apresenta a(s) voz(es) de outros locutores e perante ela(s) assume diferentes graus, maior ou menor, de comprometimento do dizer do outro.

Por ora, não trataremos aqui sobre a posição do locutor em relação aos enunciadores, uma vez que nosso foco de análise é a polifonia de locutores, mais especificamente, as ocorrências de discurso relatado no estilo direto e estilo indireto. Portanto, é sobre o discurso relatado que discorreremos na próxima seção. 
Polifonia de locutores: discurso relatado

No grupo da polifonia de locutores, Ducrot (1987) apresenta o discurso relatado sobre o qual observa-se a presença de pelo menos dois locutores distintos, sendo estes responsáveis pela parte do enunciado a eles relacionados. Vejamos a presença dos locutores no exemplo abaixo:

\section{Exemplo (01)}

O profissional de secretariado que tem habilidades técnicas e comportamentais especificas no assessoramento continuo na gestão de eventos se torna o profissional mais bem preparado para desempenhar essa atividade, Sabino e Rocha (2004, p. 94), argumentam que:

A secretária tem um grande desdobramento das suas atividades. Ela pode contribuir na organização e métodos da empresa, pode organizar eventos, pode fazer levantamentos e relatórios, é capacitada para intermediar relações e mediar conflitos, além da gama de atividades técnicas de redação, tradução, informática, arquivos etc.

Neste exemplo, percebemos nitidamente a presença de dois locutores distintos. O locutor responsável por todo o enunciado (L1) expõe a voz de outro locutor a quem chamaremos L2. Neste caso, o locutor

2 apresenta-se como uma voz correspondente a duas pessoas, Sabino e Rocha, no entanto, não podemos considerar duas vozes, mas apenas uma. Portanto, L1 apresenta L2 sendo o primeiro locutor associado a quem tem responsabilidade pelo texto como todo, ou seja, o estudante de graduação que se apresenta no próprio texto como responsável por esse projeto de pesquisa de TCC, e o segundo locutor, Sabino e Rocha.

Assim, L1 traz o discurso de L2 introduzindo-o com o verbo dicendi modalizador argumentar. Segundo Carvalho (2014), ao introduzir o discurso de L2 afirmando que esse é um argumento, L1 se posiciona perante o enunciado de L2 julgando-o e avaliando-o. Essa avaliação não exprime simplesmente o julgamento de L1 em relação ao discurso do outro, mas indica como o leitor deve ler o enunciado de L2, ou seja, deve ser lido como um argumento, um posicionamento do segundo locutor em defesa de algo.

Diante de um enunciado como o exposto no exemplo acima, Ducrot (1987) afirma existir a presença de relato no estilo direto, pois L1 reproduz, na sua materialidade, as palavras ditas por L2 e, portanto, L1 torna conhecido o discurso de L2. Assim, "relatar um discurso em estilo direto seria, pois, dizer que palavras foram utilizadas pelo autor deste 
V. 9 (2)

$237-255$

maio-ago

2019

discurso" (DUCROT, 1987, p. 186). No caso do exemplo apresentado, as palavras de L2 estão marcadas a partir do recuo de $4 \mathrm{~cm}$ da margem da folha, com letras em tamanho menor, configurando-se, portanto, uma citação em estilo direto com mais de 4 linhas.

Essa é uma forma de estruturar o discurso relatado em estilo direto muito frequente em textos de caráter acadêmico, no entanto, a língua escrita dispõe de algumas outras marcas para organização desse tipo de discurso, a saber: as aspas; travessão, os dois pontos, a introdução da voz de L2 por meio de verbos dicendi.

Outra ocorrência de discurso relatado é em estilo indireto. Vejamos o exemplo 02:

\section{Exemplo (02)}

No primeiro ponto, o PNLD (2011) considera que no LDLP as propostas de produção textual devem indicar as condições de produção (esfera, suporte, função social, gênero, destinatário), visto que, como falantes da língua portuguesa, produzimos, reconhecemos e usamos os textos em diferentes situações comunicativas como materialização dos nossos discursos, de modo que esses textos assumem características distintas de acordo com o uso que fazemos deles.

No exemplo 02, percebemos que L1 coloca em cena a voz de outro locutor, no entanto, as palavras de L2 não aparecem tais quais foram enunciadas. Dessa maneira, não há necessidade de marcas linguísticas para sinalizar a voz de L2, mas esse segundo locutor é facilmente identificado no discurso, inclusive, porque geralmente L1 introduz o discurso do outro por meio de verbos dicendi.

No trecho de exemplo acima, L1 - aluno de graduação responsável pelo projeto de pesquisa de TCC - introduz o discurso de L2 - PNLD - com um verbo modalizador considerar. Com esse verbo, L1 apresenta o discurso de L2 como uma possível verdade ou certeza. Isso porque o verbo considerar exprime a mesma conotação dos verbos refletir, pensar ou supor. Portanto, ao utilizar este verbo como introdutor do discurso de outro, L1 atenua seu comprometimento em relação ao discurso de L2, uma vez que o apresenta como uma reflexão, suposição ou pensamento. A esses verbos modalizadores que exprimem quase certeza, os estudos da Modalização classificam como verbos epistêmico quase-asseverativo (CARVALHO, 2014).

Nesse caso, não conseguimos identificar quais palavras foram utilizadas por L2 em seu discurso, mas pelo direcionamento de L1, sabemos qual a informação que pertence a L2, ou seja, L1 após usar o verbo dicendi + que consideraque - traz, logo em seguida, o relato de L2 incorporando ao seu discurso. 
Segundo Ducrot (1987), existe uma diferença entre esses dois tipos de estilo de discurso. Um é realizado para apenas conhecer a forma e o outro o conteúdo, além disso, o autor considera como caso de polifonia de locutores especificamente o discurso relatado em estilo direto. Isso porque para ele o discurso relatado em estilo indireto não é polifonia de locutores por não existir a dupla enunciação.

A diferença entre estilo direto e estilo indireto é que o primeiro daria a conhecer a forma, o segundo, só o conteúdo. O estilo direto pode também visar só o conteúdo, mas para fazer saber qual é o conteúdo, escolhe dar a conhecer uma fala (ou seja, uma sequência de palavras, imputada a um locutor) (DUCROT, 1987, p. 187).

Diante deste posicionamento, Nascimento (2009, p. 27) apresenta um contraponto. O autor afirma que a distinção entre estes dois estilos vai "além da diferença entre a forma e o conteúdo" e considera que "se trata de uma questão de grau e orientação de análise". Assim sendo, no estilo direto, L1 não se compromete com o dito pelos outros locutores (L2; L3; etc.), "uma vez que não assume a responsabilidade pelo relato dos outros locutores". No entanto, no estilo indireto, L1 se compromete com os discursos dos demais locutores pelo fato de ele ter incorporado o dito dos outros em seu discurso, ou seja, "torna seu o discurso do outro, incorporando as palavras alheias e deixando de sinalizá-las (com aspas ou travessões) como tal" (NASCIMENTO, 2009, p. 27).

Dessa forma, para Nascimento (2009), ao escolher utilizar o discurso do outro no estilo indireto, o locutor responsável pelo discurso automaticamente compromete-se com o dito como um todo, ou seja, com o discurso de outros locutores também. Caso a escolha de L1 seja a de inserir o discurso de L2 no estilo direto, ocorrerá um distanciamento entre eles, uma vez que L1 apenas apresentará o discurso de L2 e não se comprometerá com esse discurso. Portanto, a escolha pela forma de apresentação do discurso do outro, segundo Nascimento, é uma questão de grau de comprometimento, uma vez que no estilo direto há um distanciamento e no indireto, uma assimilação do discurso do outro locutor.

Nascimento (2015) reformula esse posicionamento inicial e passa a considerar que a questão de maior ou menor comprometimento, assimilação ou distanciamento está relacionada aos elementos linguístico-discursivos presentes no discurso e não por ter sido apresentado na forma de estilo direto ou indireto. Dessa forma, 
v. 9 (2)

237-255

maio-ago

2019

[...] a assimilação, o distanciamento e a avaliação do discurso relatado, por parte do locutor responsável pelo discurso, dãose muito mais pela presença de outros elementos linguísticosdiscursivos, como as aspas de diferenciação, os verbos dicendi, entre outras estratégias linguístico-discursivas, do que pelo fato de esse discurso ter sido apresentado em um ou outro estilo (NASCIMENTO, 2015, p. 347).

Concordamos com esse posicionamento de Nascimento (2015) e consideramos que tanto em discursos no estilo direto quanto em estilo indireto é possível que L1 se comprometa com o dizer de outro(s) locutor(es), dependendo dos termos linguísticos utilizados pelo locutor (a exemplo dos modalizadores discursivos). Assim sendo, L1 julgando afastar-se do discurso de L2 escolhe apresentá-lo em estilo direto. No entanto, ao introduzir o discurso alheio L1 pode compromete-se com a voz de L2 por tê-la inserido no seu discurso mediante algum posicionamento avaliativo por meio de verbos dicendi modalizadores, por exemplo.

Além desses dois tipos de discurso relatado, existe a possibilidade de o locutor responsável pelo texto como todo apresentar a voz do segundo locutor alternando entre o estilo direto e indireto.

Exemplo (03)

A respeito dessas transformações, Marcuschi (2012, p. 36) afirma que há dois momentos significativos no contexto sócio-histórico do LD "O marco inicial está diretamente relacionado à época em que os livros de uso no espaço escolar começam a ser nomeados como livros didáticos (...)" e o segundo marco provém da preocupação de se "compreender o momento atual vivenciado pelas coleções didáticas no contexto social brasileiro", pois a concepção de língua no LDPB sofreu alterações no transcorrer das últimas oito décadas.

No caso do trecho acima, percebemos que L1 opta por trazer a voz de L2 - Marcuschi - no estilo indireto introduzido pelo verbo dicendi modalizador asseverativo, "afirma", o qual apresenta o conteúdo do dito, como algo certo ou verdadeiro. Em seguida, L1 alterna o relato em estilo indireto apresentando a voz de L2 em estilo direto marcada a partir de aspas. Em discursos estruturados dessa maneira, L1 faz conhecer o conteúdo, a forma e ainda apresenta um alto grau de comprometimento com o discurso de L2 ao trazê-lo nos dois estilos e, inclusive, introduzilo por um verbo dicendi modalizador.

Portanto, de acordo com os estudos da Semântica Argumentativa, o discurso relatado em estilo direto ocorrerá quando o 
locutor responsável pelo texto expressar a voz de outro(s) locutor(es) deixando sinalizada no discurso, expressando essa voz tal qual foi dita. Já na forma de discurso indireto, para essa teoria semântica, o locutor responsável pelo enunciado interpreta o discurso de outro locutor e o expõe no seu discurso com suas palavras. No entanto, o posicionamento do locutor responsável pelo texto perante a(s) outra(s) voz(es) que ele mesmo coloca no seu texto, dependerá da forma com que ele introduziu o discurso do outro, ou seja, das construções linguístico-discursivas utilizadas no discurso.

Diante disso, a Semântica Argumentativa, por meio dos estudos da Polifonia, estuda e considera esses aspectos relacionados ao discurso relatado na forma de estilo direto e indireto. No subtópico a seguir, apresentaremos uma análise comparativa entre a GN e a SA, elucidando as similitudes e diferenças entre elas a partir das abordagens expostas nessa e nas seções anteriores.

Gramática Normativa e a Semântica Argumentativa: um comparativo sobre o discurso relatado

Como forma de sistematizar nossa análise comparativa, faremos uma retomada dos exemplos 01, 02, 03 - anteriormente analisados conforme SA - observando-os de acordo com a GN. Portanto, a partir desta análise verificaremos os pontos convergentes e divergentes entre as duas teorias.

Em primeira análise, com base na abordagem da GN, percebemos que no campo sintático a estrutura de base do estilo direto é "X disse: ' $Y$ "), do estilo indireto é "X disse que $Y$ ", enquanto que a estrutura do estilo indireto livre é "X. Y". Assim, diferentemente dos estudos da SA, a abordagem apresentada pelos gramáticos afasta-se completamente do campo de verificação do sentido produzido pelos enunciados, centrando-se, principalmente, no elemento sintático. Nos estudos da GN, a evidência é puramente gramatical, tendo como principal aspecto a normatividade da língua.

A partir do exemplo 01, verificamos que a SA classifica o trecho como ocorrência do discurso relatado de forma direta. Nesse exemplo, o locutor 1 (narrador, na perspectiva da GN) introduz a fala do segundo locutor (personagem, na perspectiva da GN) com verbo dicendi, "argumentam", mais o transpositor "que", "argumentam que". 
V. 9 (2)

$237-255$

Baseado no quadro ilustrativo (Quadro 1 - Discurso direto e indireto), compreendemos que o exemplo em análise se enquadra na característica de "enunciado subordinado, geralmente pela integrante que" sendo essa uma característica do discurso indireto. No entanto, a fala do personagem está linguisticamente sinalizada conforme regras da ABNT para citações diretas com mais de 4 linhas.

Dessa forma, trechos que possuem esse tipo de construção não são contemplados pela GN, uma vez que nele encontramos características do discurso direto como também do indireto. Assim, apesar de cumprir as normas de citação orientadas pela ABNT, ipsis litteris, da fala de outro, não podemos, à luz da Gramática Normativa, classificar o trecho do exemplo 01 como uma ocorrência de discurso direto. Do mesmo modo, não podemos classificá-lo como discurso indireto, embora a construção introdutora da fala do personagem seja de "verbo dicendi + que".

Além disso, esse trecho não é característico de uma construção no estilo de discurso indireto livre. Para ser assim classificado, as marcas composicionais do discurso direto e do discurso indireto deveriam estar apagadas, impossibilitando a percepção da construção de fala do narrador e do personagem, e isso não ocorre no exemplo em questão. Assim sendo, conforme características dos três discursos apresentados pela GN, o citado exemplo apresenta aspectos formais do discurso direto e aspectos sintáticos relativos ao discurso indireto, portanto, não há classificação conforme a GN.

No exemplo 02, por não ser possível identificar exatamente a fala do segundo locutor - L2 - (personagem, na GN), poderíamos pensar que esse trecho se classifica como discurso indireto livre, pois compreenderíamos que esse é um trecho de fala uníssono, de acordo com a GN. No entanto, por mais que os limites da fala do L2 não estejam nitidamente visíveis no discurso, o locutor 1 (narrador, na GN) utiliza o verbo dicendi (considera) + o transpositor "que" como introdutores de discurso alheio. Esse uso dentro de construções subordinadas é característica de enunciados classificados de discurso indireto para a GN e não de discurso indireto livre.

Dessa maneira, a análise realizada a partir da GN no exemplo 02 é semelhante à realizada pela SA em seu aspecto classificatório. Contudo, a investigação da SA não se limita apenas ao aspecto estrutural/ gramatical, mas verifica-se também o comportamento semântico dos termos introdutores do discurso a fim de compreender o grau de comprometimento dos sujeitos participantes do discurso em relação ao dito. Essas, por sua vez, são abordagens não contempladas pela GN. 
Do mesmo modo que no exemplo 02, no exemplo 03 a fala de L2 (personagem, na GN) parece ter sido incorporada a L1 (narrador, na GN). Porém, nesse último exemplo, L1 optou por sinalizar a fala de L2, diferentemente do que ocorre no exemplo 02, mas semelhantemente ao que foi realizado por L1 no exemplo 01.

Portanto, no exemplo 03, em relação à forma, L1 marca linguisticamente a fala de L2 por meio de aspas, mas apresenta o discurso na estrutura de discurso indireto, conforme GN, utilizando a voz marcada de L2 de maneira intercalada à construção de fala de L1. Assim, no exemplo 03 percebemos que L1 traz o discurso na forma indireta, pois utiliza construção subordinada introduzida pelo verbo dicendi "afirmar" + o transpositor "que" - "afirma que". Por mais que em alguns momentos a fala de L2 esteja evidenciada no trecho a partir das aspas, a forma estrutural do discurso, segundo a GN, não permite que a classificação seja de discurso em estilo direto, mas de discurso em estilo indireto, em razão do critério sintático "X disse que $\mathrm{Y}^{\prime \prime}$.

Diante disso, percebemos que enquanto a GN, mediante abordagem dos gramáticos CUNHA (1979) e Bechara (2006), não apresenta classificação para o exemplo 01, a SA o classifica como ocorrência de discurso relatado em estilo direto. Em relação ao exemplo 02, percebemos semelhança na classificação baseada na GN e SA, uma vez que ambas consideram esse trecho como discurso indireto. Além disso, à luz da GN, o exemplo 03 é característico de discurso em estilo indireto, porém para a SA esse é um trecho de discurso em estilo direto que combina estilo indireto e estilo direto, sobressaindo-se o estilo direto, em razão do uso das aspas, as quais sinalizam a reprodução da voz alheia.

\section{Considerações finais}

O objetivo principal deste artigo foi verificar a abordagem do discurso relatado pela GN, como também pela SA, traçando um paralelo entre elas. Foi nesse sentido que após sintetizar a classificação da GN sobre o discurso relatado, apresentamos resumidamente algumas considerações acerca da Teoria Polifônica da Enunciação de Ducrot, como também tecemos as considerações da SA em relação ao discurso relatado, uma das formas de polifonia de locutores e após isso estabelecemos um comparativo entre as duas abordagens. 
v. 9 (2)

237-255

Com a análise com base na SA, verificamos que um dos três exemplos observados compreende uma ocorrência de discurso relatado em estilo direto, o outro, em estilo indireto e o terceiro, em direto e indireto. Essa análise mostrou que a teoria da SA verifica o funcionamento dos discursos relatados em enunciados reais, levando em consideração tanto sua característica estrutural, quanto o aspecto semântico. Assim, a citada teoria considera o grau de comprometimento do sujeito responsável pelo discurso diante das vozes que ele coloca em cena no enunciado, isso a partir da verificação dos termos introdutores da voz do outro.

Apartir daanáliseapresentada sobabordagem da GN, percebemos que as considerações da SA são distintas da GN. Enquanto aquela observa o funcionamento a partir das características composicionais somadas à semântica resultante de cada ocorrência de discurso relatado, essa observa apenas o aspecto estrutural, tendo em vista o caráter sintático peculiar do discurso direto, indireto ou indireto livre.

Assim, podemos concluir que mesmo apresentando abordagens divergentes, cada uma das teorias decorre sua análise de discurso relatado a partir do que elas mesmas se propõem. Ou seja, a proposta da SA é perceber ocorrências reais de discurso, a fim de verificar o comportamento dos sujeitos envolvidos nele e o funcionamento dos enunciados. Diferentemente da SA, a GN tem como foco de análise os aspectos relativos às estruturas sintática das construções. Portanto, cabe aos estudiosos da língua(gem), ao verificar ocorrências de discursos relatados, buscar compreender as peculiaridades relativas às diferentes abordagens entre as teorias e optar pela análise das ocorrências com base em uma ou outra perspectiva teórica.

\section{Referências}

BAKHTIN. Estética da criação verbal. Tradução M.E.G. Gomes. 3. ed. São Paulo: Martins Fontes, 2000.

BECHARA, Evanildo. Moderna gramática portuguesa. 37. ed. Rio de Janeiro: Lucerna, 2006.

CARVALHO, A. G. 0 arrazoado por autoridade e a modalização discursiva: estratégias de argumentação no gênero Projeto de Pesquisa de TCC. 2014. 147f. Dissertação (Mestrado - Programa de Pós-Graduação em Linguística). Universidade Federal da Paraíba, João Pessoa, 2014.

CUNHA, Celso Ferreira da. Gramática da língua portuguesa. 5. ed. Rio de Janeiro: FENAME, 1979. 
DUCROT, Oswald. O dizer e o dito. Tradução por Eduardo Guimarães. Campinas, SP: Pontes. Tradução de Le dire et le dit. 1987.

Polifonia y argumentacion. Universidade del Valle - Cali. 1988.

NASCIMENTO, Erivaldo Pereira. Jogando com as vozes do outro: argumentação na notícia jornalística. João Pessoa: Editora Universitária da UFPB, 2009.

A polifonia nos gêneros acadêmicos e formulaicos: a construção de sentidos a partir da evocação da palavra alheia. Porto Alegre: Revista Letras de Hoje, v. 50. 2015.

TRAVAGLIA, Luiz Carlos. Gramática e interação: uma proposta para o ensino de gramática no $1^{\circ}$ e $2^{\circ}$ graus. 6. ed. São Paulo: Cortez, 2001. 